\title{
Fungal diversity of root vegetables and soil rhizosphere collected from organic and conventional farms in Eastern Poland
}

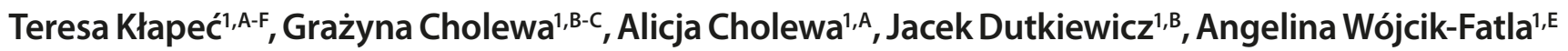 \\ ${ }^{1}$ Department of Biological Health Hazards and Parasitology, Institute of Rural Health, Lublin, Poland \\ A - Research concept and design, B - Collection and/or assembly of data, C - Data analysis and interpretation, \\ $D$ - Writing the article, E - Critical revision of the article, $F$ - Final approval of article
}

\begin{abstract}
Kłapeć T, Cholewa G, Cholewa A, Dutkiewicz J, Wójcik-Fatla A. Fungal diversity of root vegetables and soil rhizosphere collected from organic and conventional farms in Eastern Poland. Ann Agric Environ Med. 2018; 25(2): 374-381. doi: 10.26444/aaem/92143
\end{abstract}

\begin{abstract}
I Abstract
Objective. Determination of the concentration and species composition of filamentous fungi in root vegetables (carrots and red beetroots), and the adjacent rhizosphere soil, collected on organic and conventional farms in Eastern Poland.

Materials and method. During the period 2015-2016, a total number of 80 samples of vegetables and 40 samples of soil were examined. From each type of farm, 20 samples of vegetables and 20 samples of the adjacent soil were examined. In addition, the study included 20 samples of vegetables from organic farms and 20 samples of vegetables from conventional farms purchased on the markets in the city of Lublin in Eastern Poland. In order to determine the concentration and species composition of filamentous fungi, both in vegetables and soil, the method of plate dilutions on Malt Agar medium (Difco) with chloramphenicol was used. The study was conducted in two parallel repetitions. Inoculated media were incubated at the temperature of $30^{\circ} \mathrm{C}$ for 72 hours, then at room temperature for 72 hours. The species composition of fungal flora was determined using macroscopic and microscopic methods, with the help of keys and atlases.

Results. It was found that the mean concentration of fungi was higher in vegetables and soil from conventional farms than in those from organic farms. In the case of carrots and soil from conventional farms, this concentration was 4.93 and 5.10 $\log _{10}$ CFU g ${ }^{-1}$, respectively, whereas from organic farms - respectively, 3.81 and $4.20 \log _{10}$ CFU g ${ }^{-1}$. In the case of beetroots and soil from conventional farms, the mean concentrations were also higher compared to organic farms $-5.09 \mathrm{vs.} 3.93$ and 4.95 vs. $4.23 \log _{10}$ CFU g ${ }^{-1}$. In the examined vegetables and rhizosphere soil, 61 species of filamentous fungi were found, of which 12 belonged to the genus Penicillium, 4 to the genus Fusarium, and 2 species each to the genera: Aspergillus, Cladosporium and Trichoderma. As many as 28 (45.9\%) fungal species that occurred in vegetables and soil are regarded as pathogenic for humans.
\end{abstract}

\section{Key words}

filamentous fungi, vegetables, rhizosphere soil, organic and conventional farms

\section{INTRODUCTION}

A great increase in vegetable consumption that has been observed globally in the past 20 years, is largely due to the fact that they provide health-promoting diet supplements, such as vitamins, minerals, antioxidants and fibres $[1,2]$. Organic farming that keeps to environmentally-friendly principles, without using artificial chemicals and genetic modifications, greatly contributes to the development of the vegetable branch of agriculture and is generally recognized as safe for consumers, in spite of some earlier reservations concerning the use of manure as a potential source of pathogenic microorganisms $[2,3,4,5,6]$.

Outbreaks of acute gastrointestinal disease after the consumption of vegetables were reported from many countries worldwide. Bacteria, viruses and parasites of different origin, but never fungi, have been identified as causative agents of these diseases. This fact contributes to the inaccurate view that fungi occurring in vegetables do not pose any significant hazard for consumers. In fact, although

Address for correspondence: Teresa Kłapeć, Department of Biological Health Hazards and Parasitology, Institute of Rural Health, Jaczewskiego 2, 20-090 Lublin, Poland

e-mail: teresaklapec@op.pl

Received: 06.03.2018; accepted: 11.06.2018; first published: 15.06.2018 filamentous fungi rather do not evoke any acute disease after the consumption of vegetables, they do represent a potential cause of chronic diseases which may be evoked by mycotoxins, secondary metabolites able to elicit severe systemic diseases, by allergic reactions, or by infections caused by fungi which are opportunistic pathogens $[7,8]$.

Nevertheless, knowledge about the potential risk caused by the presence of potentially pathogenic fungi in vegetables is small, especially if compared with bacteria. Accordingly, the aim the present study was to determine the presence, concentration, species composition and potential pathogenic significance of filamentous fungi in two root vegetables (carrot and beetroot) which have been little studied in this respect. Samples of vegetables and adjacent rhizosphere soil were collected and examined from both organic and conventional farms in eastern Poland, an important agricultural region in the European Union.

\section{MATERIALS AND METHOD}

Sampling. During the period 2015-2016, microbiological studies were conducted of carrots (Daucus carota L.) and red beetroots (Beta vulgaris L.), as well as soil adjacent to these vegetables, on conventional and organic farms. Samples of 
vegetables and soil were collected on 10 conventional and 10 organic farms located in the Lublin Province of Eastern Poland. From each farm, one sample of carrot and one sample of beetroot was collected, plus one sample of rhizosphere soil adjacent to carrot and one adjacent to beetroot. A total of 20 samples of vegetables and rhizosphere soil were taken on organic farms and 20 samples of vegetables and 20 samples of rhizosphere soil were taken on conventional farms. In addition, the study included 20 samples of vegetables originating from conventional farms and purchased on the markets in the city of Lublin in Eastern Poland (10 samples each of carrots and beetroots), and 20 samples of vegetables originating from organic farms and sold on the markets (10 samples of carrots and beetroots each). Vegetables were bought in the autumn and examined immediately after purchase. Summarizing, 80 samples of vegetables and 40 samples of adjacent rhizospere soil were examined in the course of the present study.

Preparation of the samples of vegetables. The samples of vegetables (each sample consisted of 10 roots collected at various sites of the field) were collected in fields at random, separately packed into clean foil bags, and then transported to the laboratory. In the laboratory, a mean sample was prepared by mixing the collected roots. Vegetables purchased on the market were also packed into clean foil bags and transported to the laboratory.

Subsequently, the roots of carrots and beetroots were loosely shaken for cleaning of soil and cut into smaller pieces using a sterile scalpel. 20 gram samples of fragmented vegetables were homogenized with the Universal Laboratory AID type 309 homogenizer for $5 \mathrm{~min}$ in $180 \mathrm{ml}$ of a diluent (Ringer's solution), with the addition of Tween 80. From the homogenates prepared in this way dilutions were performed, which were used for cultures.

Preparation of soil samples. Soil for the study was collected in the same fields as vegetables, by the envelope method. From each field, 5 soil sub-samples were collected from different sites. After transportation to the laboratory, the mean sample was prepared by mixing the sub-samples collected. Soil was crushed, mixed and put through a sieve with $2 \mathrm{~mm}$ openings. From the mean sample prepared in this way, 10 gram soil samples were suspended in $90 \mathrm{ml}$ Ringer's solution with the addition of Tween 80 . The samples were shaken for 10 minutes, and subsequently dilutions were prepared, which were used for cultures.

Determining of concentrations and species composition of filamentous fungi in vegetables and soil. In order to determine the concentrations and species composition of filamentous fungi, both in vegetables and soil, the method of plate dilutions on malt agar (Difco, USA) with chloramphenicol was used, by spreading $0.1 \mathrm{ml}$ of each dilution on the agar surface. The study was conducted in two parallel repetitions. Inoculated media were incubated at the temperature of $30^{\circ} \mathrm{C}$ for 72 hours, then at room temperature $\left(22^{\circ} \mathrm{C}\right)$ for 72 hours. The numbers of microorganisms were expressed as decimal logarithms of the numbers of colony forming units (CFU) in $1 \mathrm{~g}$ of the examined material $\left(\log _{10}\right.$ CFU g-1).

The species composition of fungal flora was determined using macroscopic and microscopic methods, with the help of keys and atlases $[9,10,11]$.
Determining of the enzymatic activity of isolated fungi. Selected strains of filamentous fungi isolated from carrot or beetroot (a total of 13 strains) were inoculated on CzapekDox broth (Beckton, Dickinson and Co., USA) with and without supplementation with $1 \%$ of minced homologous vegetable (carrot or beetroot). After 24 days of incubation at $24^{\circ} \mathrm{C}$, culture supernatants obtained by centrifugation were examined with the API ZYM microtests (bioMérieux, France), according to manufacturer's instructions, for detection of extracellular hydrolytic enzymes.

Statistical analysis. The results were analyzed by MannWhitney and Spearman non-parametric tests, using STATISTICA v. 5.1 package (Statsoft, Tulsa, OK, USA).

\section{RESULTS}

Concentrations of filamentous fungi in root vegetables and adjacent rhizosphere soil.

Carrot. The median concentrations of fungi isolated from fresh vegetables (FV) and rhizosphere soil (RS) on conventional farms amounted to 4.93 and $5.10 \log _{10} \mathrm{CFU}$ $\mathrm{g}^{-1}$, respectively, and were significantly $(\mathrm{P}<0.01)$ greater than the analogous values on organic farms -3.81 and 4.20 $\log _{10}$ CFU g ${ }^{-1}$, respectively (Tab. 1). A significant correlation $(\mathrm{P}<0.05)$ was found between the fungal concentrations in fresh carrot and surrounding soil, both on conventional and organic farms, in spite of the fact that on organic farms the concentration of fungi in soil was significantly greater compared to fresh vegetable $(\mathrm{P}<0.001)$.

By contrast, the median concentration of fungi in carrot from organic farms sold at retail (VR) was significantly greater compared to that from conventional farms (3.93 vs. $\left.3.48 \log _{10} \mathrm{CFU} \mathrm{g}{ }^{-1}, \mathrm{P}<0.001\right)$. The FV and VR median concentrations for organic farms were almost identical (3.81 vs. $3.93 \log _{10} \mathrm{CFU} \mathrm{g}{ }^{-1}$ ), whereas for conventional farms the median FV concentration was significantly greater compared to VR value (4.93 vs. $3.48 \log _{10}$ CFU g-1, $\mathrm{P}<0.001$ ) (Tab. 1 ).

Beetroot. The results recorded in the mycological examinations of beetroots and adjacent soil were similar to those observed in the case of carrot. The median FV and VR concentrations of fungi on conventional farms were also greater compared to organic farms (5.09 vs. 3.93 and 4.95 vs. $4.23 \log _{10}$ CFU g-1, respectively), but the differences did not attain a significance level (Tab. 1). In the examined beetroots, a significant correlation was also found between the FV and RS concentrations both on conventional and organic farms, and on organic farms the median RS concentration of fungi was significantly greater compared to FV concentration $(\mathrm{P}<0.01)$.

Similar to the case of carrot, the median FV and VR concentrations for organic farms were very similar (3.93 vs. $4.10 \log _{10} \mathrm{CFU} \mathrm{g^{-1 }}$, whereas for conventional farms the median FV concentration was insignificantly greater compared to VR value (5.09 vs. $3.90 \log _{10} \mathrm{CFU} \mathrm{g}^{-1}$ ) (Tab. 1).

Species composition of filamentous fungi in root vegetables and their rhizosphere soil.

Carrot. The species composition of filamentous fungi isolated from carrot and its rhizosphere soil is presented in Figure 1. The most numerous were Penicillium strains which formed, 
Table 1. Population of filamentous fungi in root vegetables and their rhizosphere soil in Eastern Poland

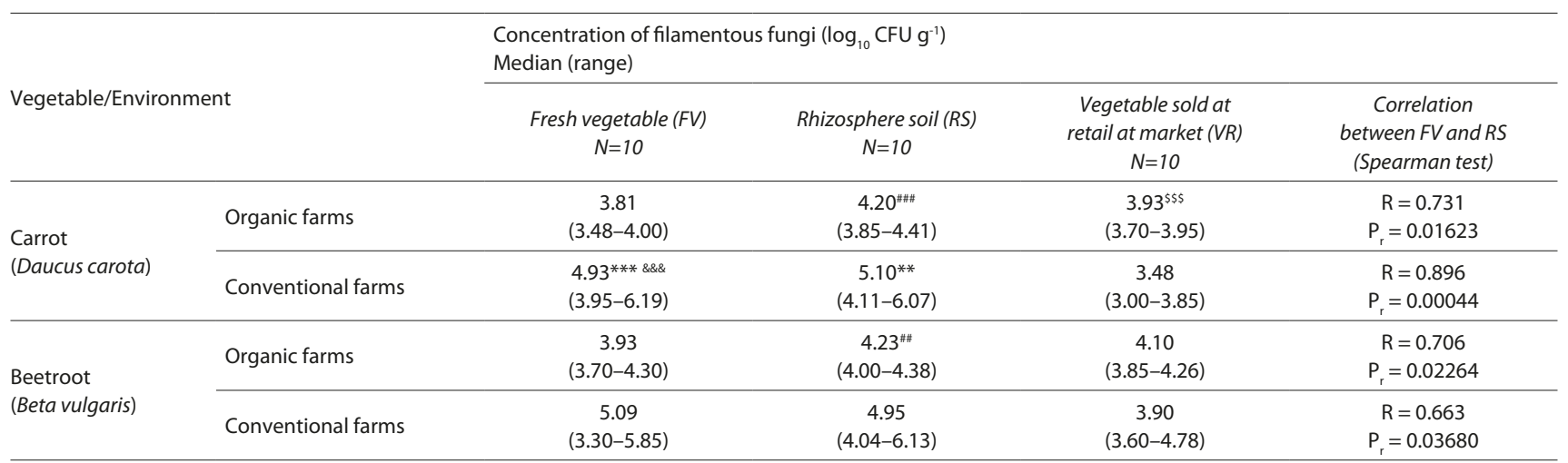

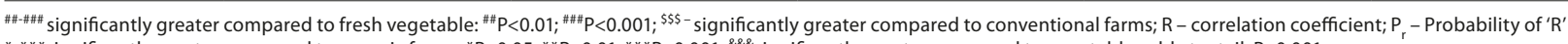
${ }^{*}$-***significantly greater compared to organic farms: ${ }^{*} \mathrm{P}<0.05 ;{ }^{* *} \mathrm{P}<0.01 ;{ }^{* * *} \mathrm{P}<0.001$; \&\&\& significantly greater compared to vegetable sold at retail, $\mathrm{P}<0.001$

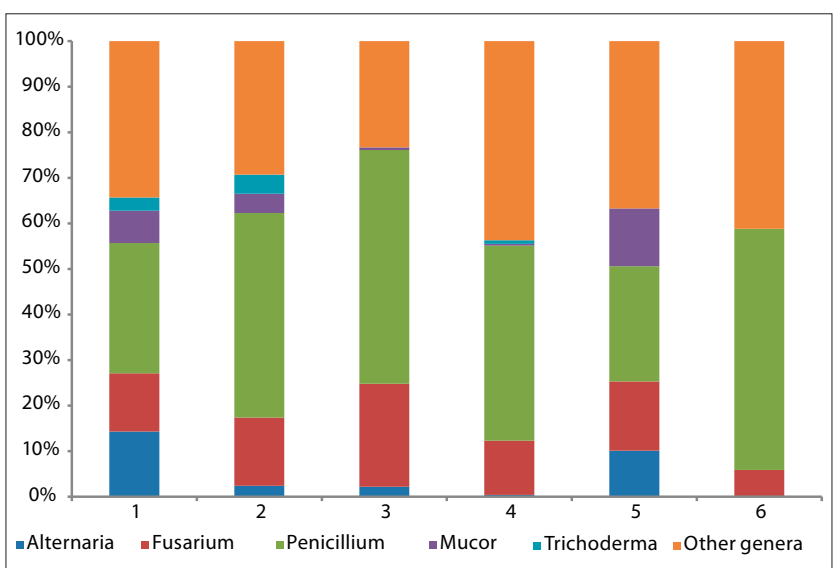

Figure 1. Species composition of fungi isolated from carrot and its rhizosphere soil. Numerals under the $\mathrm{X}$ axis denote following samples: 1) Fresh carrot from the soil organic farms. 2) Fresh carrot from the soil, conventional farms. 3) Rhizosphere soil, organic farms.4) Rhizosphere soil, conventional farms. 5) Carrot from organic farms sold at retail. 6) Carrot from conventional farms sold at retail

on average, $28.6 \%, 44.9 \%$ and $25.3 \%$ of total fungi isolated from FV, RS and VR samples on organic farms, respectively, and $51.3 \%, 42.8 \%$, and $52.9 \%$ of total fungi isolated from FV, $\mathrm{RS}$ and VR samples on conventional farms, respectively. Also relatively commonly found were fungi belonging to the genus Fusarium, which accounted for $5.9-22.6 \%$ and $12.8-15.2 \%$ of total fungi isolated on organic and conventional farms, respectively, whereas strains of the genera Alternaria, Mucor and Trichoderma were less numerous, forming together $10.8-24.3 \%$ and $1.6-2.8 \%$, respectively. Strains belonging to 15 other genera formed together $29.3-30.6 \%$ and $23.3-43.7 \%$ of total fungi isolated on the organic and conventional farms, respectively.

The full list of fungal species identified in the FV, RS and VR samples of carrot collected on organic and conventional farms is presented in Table 2. A total of 48 species of filamentous fungi belonging to 20 genera were identified in these samples, mostly those classified as Penicillium (13 species) and Fusarium (5 species). Of the identified species, 19 were common for fresh vegetable and adjacent soil, whereas only 7 were common for fresh vegetable and vegetable sold at retail. More species were isolated on conventional farms and markets compared to organic ones (36 vs. 27).

Beetroot. The species composition of filamentous fungi isolated from beetroot and its rhizosphere soil is presented

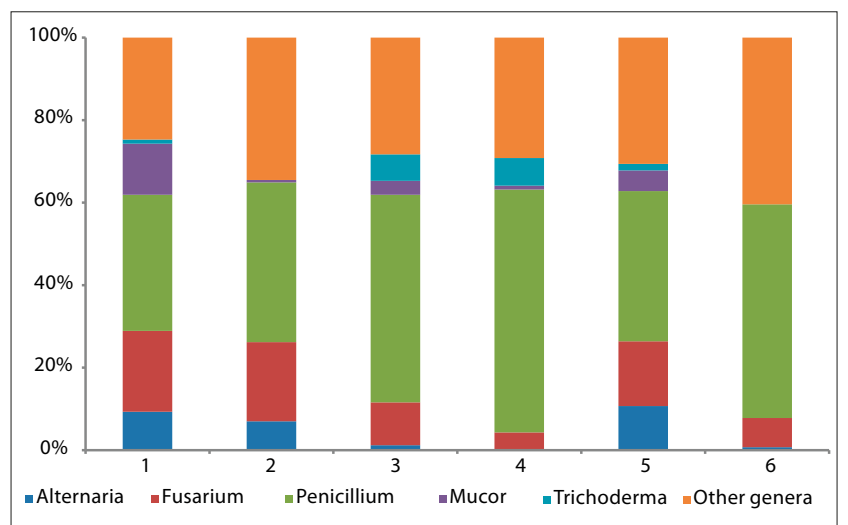

Figure 2. Species composition of fungi isolated from beetroot and its rhizosphere soil.

Numerals under the $X$ axis denote following samples: 1) Fresh beetroot from the soil, organic farms. 2) Fresh beet from the soil, conventional farms. 3) Rhizosphere soil, organic farms. 4) Rhizosphere soil, conventional farms. 5) Beetroot from organic farms sold at retail. 6) Beet from conventional farms sold at retail

in Figure 2. Similar to carrot, the most numerous were Penicillium strains which formed. on average, 33.0\%, 50.5\% and $36.4 \%$ of total fungi isolated from FV, RS and VR samples on organic farms, respectively, and $38.7 \%, 58.9 \%$, and $51.8 \%$ of total fungi isolated from FV, RS and VR samples on conventional farms, respectively. Fungi belonging to the genus Fusarium were also common and accounted for $10.4-19.6 \%$ and $4.3-19.2 \%$ of total fungi isolated on organic and conventional farms, respectively. Strains of the genera Alternaria, Mucor and Trichoderma formed together 11.0$22.7 \%$ and $0.7-7.6 \%$, respectively, whereas strains belonging to remaining 14 genera formed together $24.7-30.6 \%$ and $29.2-$ $40.4 \%$ of total fungi isolated on the organic and conventional farms, respectively.

The number of fungal species identified in the FV, RS and VR samples of beetroot collected on organic and conventional farms was slightly greater than in carrot, and amounted to 51 species belonging to 19 genera, mostly Penicillium (18 species) and Fusarium (5 species) (Tab. 3). Of these, 15 species were common for fresh vegetable and adjacent soil, while 14 were common for fresh vegetable and vegetable sold at retail. Similar to the case of carrot, more species were isolated on conventional farms and markets compared to organic ones (42 vs. 25$)$. 
Table 2. Species of filamentous fungi isolated from the samples of carrot and adjacent soil

\begin{tabular}{ll}
\hline A. Organic farms and markets & \\
\hline Acremonium strictum (VR) & Penicillium citreonigrum (citreoviride) (RS) \\
\hline Acremonium spp. (RS, VR) & Penicillium expansum (VR) \\
\hline Alternaria alternata (RS) & Penicillium funiculosum (VR) \\
\hline Alternaria spp. (FV, RS, VR) & Penicillium glabrum (FV, VR) \\
\hline Aspergillus oryzae (FV) & Penicillium spp. (FV, RS, VR) \\
\hline Aspergillus versicolor (RS) & Purpureocillium lilacinum (RS) \\
\hline Chaetomium spp. (FV, RS) & Rhizopus oryzae (RS) \\
\hline Cladosporium spp. (FV, RS) & Rhizopus spp. (FV) \\
\hline Fusarium solani (FV) & Scopulariopsis spp. (FV, RS) \\
\hline Fusarium spp. (FV, RS, VR) & Stemphylium spp. (RS, VR) \\
\hline Monascus spp. (RS) & Trichoderma harzianum (RS) \\
\hline Mucor racemosus (FV, RS) & Trichoderma spp. (FV, RS) \\
\hline Mucor spp. (FV, RS, VR) & Ulocladium spp. (VR) \\
\hline Paecilomyces spp. (RS) & \\
\hline
\end{tabular}

\section{B. Conventional farms and markets}

\begin{tabular}{|c|c|}
\hline Acremonium murorum (VR) & Paecilomyces spp. (FV, RS) \\
\hline Acremonium strictum (FV, RS, VR) & Penicillium chrysogenum (notatum) (FV) \\
\hline Acremonium spp. (VR) & Penicillium citrinum (VR) \\
\hline Alternaria alternata (FV) & Penicillium crustosum (notatum) (RS) \\
\hline Alternaria spp. (RS) & Penicillium decumbens (RS) \\
\hline Aureobasidium spp. (RS) & Penicillium expansum (FV, RS) \\
\hline Chaetomium spp. (RS) & Penicillium funiculosum (RS, VR) \\
\hline Cladosporium herbarum (FV) & Penicillium glabrum (FV, RS) \\
\hline Cladosporium sphaerospermum (FV, RS) & Penicillium griseofulvum (urticae) (RS) \\
\hline Curvularia spp. (FV) & Penicillium olsonii (FV) \\
\hline Fusarium culmorum (FV, RS) & Penicillium paneum (FV) \\
\hline Fusarium oxysporum (FV, RS) & Penicillium spp. (FV, RS) \\
\hline Fusarium proliferatum (FV) & Purpureocillium lilacinum (FV, RS) \\
\hline Fusarium solani (FV, RS) & Rhizomucor spp. (FV) \\
\hline Fusarium spp. (FV, RS, VR) & Rhizopus stolonifer (FV, RS) \\
\hline Lichtheimia (Absidia) spp. (FV, RS, VR) & Trichoderma spp. (RS) \\
\hline Mucor circinelloides (FV) & Ulocladium spp. (RS) \\
\hline Mucor spp. (FV, RS) & Verticillium spp. (FV, RS) \\
\hline
\end{tabular}

Explanation: $\mathrm{FV}$ = fresh vegetable; $\mathrm{RS}$ = rhizosphere soil; $\mathrm{VR}$ = vegetable sold at retail

\section{Enzymatic activity of fungal strains isolated from root vegetables and adjacent soil.}

Results viewed by enzymes tested. Enzymatic activity of 13 species of filamentous fungi isolated from examined vegetables and adjacent soil showed a marked variability depending on enzyme. A marked average activity $(>2.0$ in the arbitrary scale $0-5.0$ ) was noted in the case of 7 enzymes (36.8\% of the total enzymes tested): alkaline phosphatase, C8 esterase, leucine arylamidase, acid phosphatase, naphtholAS-BI-phosphohydrolase, $\beta$-glucosidase and $\mathrm{N}$-acetyl- $\beta$ glucosaminidase (Fig. 3). In contrast, a very weak activity $(<0.5)$ was observed in the case of 6 other enzymes: cystine arylamidase, $\alpha$-chymotrypsin, $\beta$-glucuronidase, $\alpha$-glucosidase, $\alpha$-mannosidase, $\alpha$-fucosidase. The activity of the remaining 6 enzymes was between $0.5-2.0$ of the arbitrary scale.
Table 3. Species of filamentous fungi isolated from the samples of beetroot and adjacent soil

\begin{tabular}{ll}
\hline A. Organic farms and markets & \\
\hline Acremonium murorum (VR) & Paecilomyces spp. (RS, VR) \\
\hline Acremonium spp. (FV, VR) & Penicillium citrinum (RS) \\
\hline Alternaria glomerata (FV) & Penicillium expansum (FV, RS, VR) \\
\hline Alternaria spp. (FV, RS, VR) & Penicillium funiculosum (VR) \\
\hline Aspergillus clavatus (RS) & Penicillium glabrum (FV, RS, VR) \\
\hline Aureobasidium spp. (VR) & Penicillium griseofulvum (urticae) (RS) \\
\hline Chaetomium spp. (FV, RS) & Penicillium spp. (FV, RS, VR) \\
\hline Chaetomium atrobruneum (VR) & Purpureocillium lilacinum (RS, VR) \\
\hline Curvularia spp. (RS) & Rhizopus spp. (FV) \\
\hline Fusarium spp. (FV, RS, VR) & Stemphylium spp. (RS, VR) \\
\hline Mucor racemosus (FV) & Trichoderma viride (FV) \\
\hline Mucor spp. (FV, RS, VR) & Trichoderma spp. (RS, VR) \\
\hline & Ulocladium spp. (FV, VR) \\
\hline
\end{tabular}

\section{B. Conventional farms and markets}

\begin{tabular}{ll}
\hline Acremonium murorum (VR) & $\begin{array}{l}\text { Penicillium citreonigrum } \\
\text { (citreoviridae) (RS, VR) }\end{array}$ \\
\hline Acremonium strictum (RS, VR) & Penicillium citrinum (RS) \\
\hline Acremonium spp. (FV, VR) & Penicillium corylophilum (VR) \\
\hline Alternaria alternata (FV) & Penicillium crustosum (RS) \\
\hline Alternaria spp. (FV, VR) & Penicillium digitatum (FV) \\
\hline Aspergillus versicolor (RS) & Penicillium expansum (FV) \\
\hline Aspergillus pp. (VR) & Penicillium glabrum (FV, RS, VR) \\
\hline Chaetomium spp. (RS) & Penicillium griseofulvum (urticae) (RS) \\
\hline Curvularia spp. (FV) & Penicillium lehmanii (VR) \\
\hline Fusarium culmorum (FV, RS) & Penicillium macrosporum (VR) \\
\hline Fusarium oxysporum (FV, RS) & Penicillium nalgiovense (RS) \\
\hline Fusarium proliferatum (FV) & Penicillium paneum (FV) \\
\hline Fusarium solani (FV) & Penicillium penicillioides (VR) \\
\hline Fusarium spp. (FV, RS, VR) & Penicillium variabile (RS) \\
\hline Geomyces pannorum (RS) & Penicillium spp. (FV, RS, VR) \\
\hline Lichtheimia (Absidia) spp. (RS, VR) & Purpureocillium lilacinum (FV, RS) \\
\hline Microsporum spp. (RS) & Rhizopus stolonifer (FV, RS, VR) \\
\hline Mucor spp. (FV, RS) & Trichoderma viride (RS) \\
\hline Paecilomyces spp. (RS) & Trichoderma spp. (RS) \\
\hline Penicillium chrysogenum (notatum) (FV) & Verticillium spp. (FV) \\
\hline Ulocladium spp. (FV) \\
\hline aurantiogriseum (cyclopium) (RS)
\end{tabular}

FV - fresh vegetable; RS - rhizosphere soil; VR - vegetable sold at retail

It is noteworthy, that in most cases (15 out of $19-79 \%)$ the enzymatic activity was distinctly greater if tested on the medium supplemented with minced vegetable, identical with the source of the strain's isolation. However, because of the limited number of strains tested, the difference proved to be significant only in the case of naphthol-AS-BIphosphohydrolase $(\mathrm{P} \leq 0.05)$.

Results viewed by fungal species tested. The mean enzymatic activity of 13 fungal species was moderate, ranging for all the strains from 1.0-2.0 for the total battery of 19 enzymes tested (Fig. 4). The strongest activity (>1.5) was revealed by Acremonium strictum, Alternaria alternata, Chaetomium spp., Cladosporium sphaerospermum and Fusarium culmorum. 


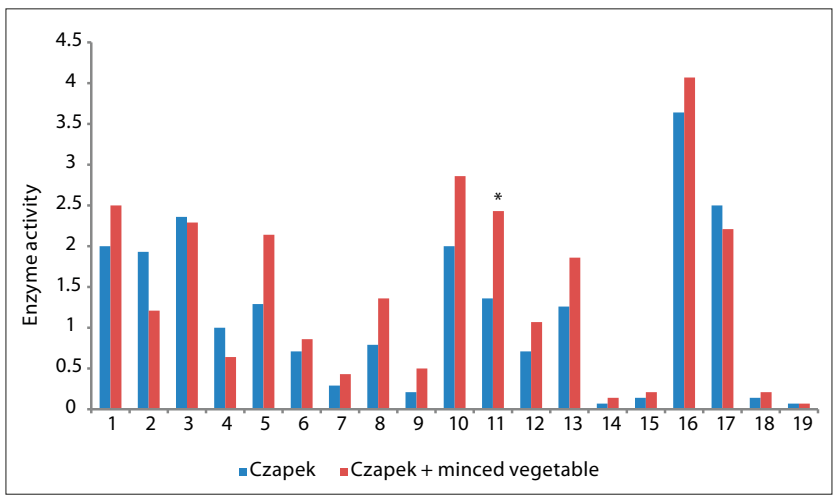

Figure 3. Enzyme activity of fungal strains shown by enzymes tested. Numerals under the $X$ axis denote following enzymes: 1) Alkaline phosphatase. 2) C4 esterase. 3) C8 esterase. 4) C14 lipase. 5) Leucine arylamidase. 6) Valine arylamidase. 7) Cystine arylamidase. 8) Trypsin. 9) $\alpha$-chymotrypsin. 10) Acid phospahatase. 11) Naphthol-AS-BI-phosphohydrolase. 12) $\alpha$-galactosidase. 13) $\beta$-galactosidase. 14) $\beta$-glucuronidase. 15) $\alpha$-glucosidase. 16) $\beta$-glucosidase. 17) $\mathrm{N}$-acetyl- $\beta$-glucosaminidase. 18) $\alpha$-mannosidase. 19) $\alpha$-fucosidase.

* enzyme activity of fungal strains grown on liquid Czapek medium supplemented with minced vegetable was significantly greater compared to those grown on standard Czapek medium $(\mathrm{P} \leq 0.05)$

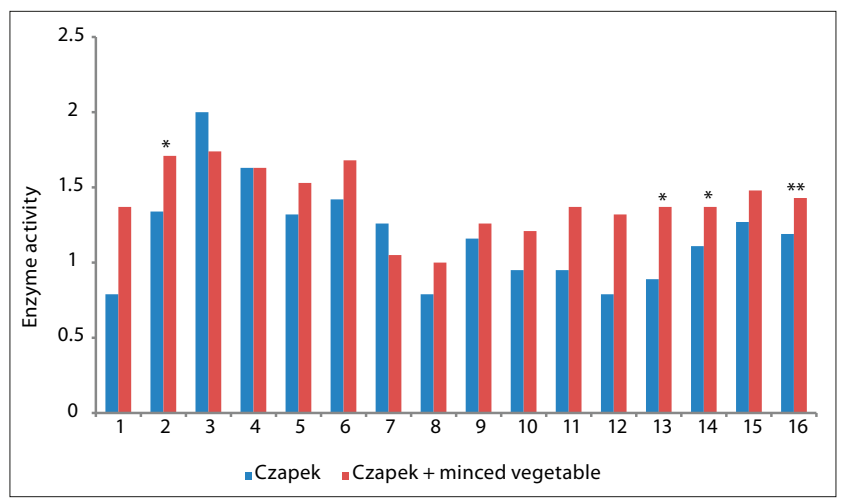

Figure 4. Enzyme activity of fungal strains shown by species tested.

Numerals under the $\mathrm{X}$ axis denote following fungal species, or groups of species: 1) Absidia sp. 2) Acremonium strictum. 3) Alternaria alternata. 4) Chaetomium sp. 5) Cladosporium sphaerospermum. 6) Fusarium culmorum. 7) Fusarium oxysporum. 8) Fusarium solani. 9) Fusarium sp. 10) Penicillium expansum. 11) Penicillium glabrum. 12) Rhizopus stolonifer. 13) Trichoderma viride. 14) Total species isolated from carrot or adjacent soil. 15) Total species isolated from beetroot or adjacent soil. 16) Total species isolated from both root vegetables (carrot + beetroot).

* - ** enzyme activity of fungal strains grown on liquid Czapek medium supplemented with minced vegetable was significantly greater compared to those grown on standard Czapek medium; * $\mathrm{P} \leq 0.05$; ** $\mathrm{P} \leq 0.01$.

Increments of enzymatic activity by supplementation of the test medium with homogenous vegetable were observed in 10 out of 13 fungal species tested (77\%). Differences proved to be significant for Acremonium strictum and Trichoderma viride $(\mathrm{P} \leq 0.05)$, as well as for total strains isolated from carrot $(\mathrm{P} \leq 0.05)$ and total strains isolated from both root vegetables examined ( $\mathrm{P} \leq 0.01)$ (Fig. 4).

\section{DISCUSSION}

Levels of filamentous fungi in root vegetables and adjacent soil. The median concentrations of filamentous fungi in examined vegetables were $3.49-5.0 \log _{10} \mathrm{CFU} \mathrm{g} \mathrm{g}^{-1}$, being in the middle of values reported for fungi (moulds and yeasts) determined in the fresh and whole vegetables collected in various countries of the world, which varied within a fairly wide range of $1.1-6.1 \log _{10} \mathrm{CFU} \mathrm{g}^{-1}[2,3,12,13]$. Concentrations of filamentous fungi in carrot and beetroot determined in the presented study were similar to the concentrations of aerobic mesophilic bacteria found in these vegetables on conventional farms [14].

The concentrations of filamentous fungi in rhizosphere soil adjacent to vegetables, in most cases, were slightly greater than in the vegetables themselves. A significant correlation between the fungal concentrations in fresh vegetables and soil was found, which confirms the view of Lugauskas et al. [8] that most of the filamentous fungi detected in vegetables originates from soil.

Species composition of filamentous fungi in root vegetables and adjacent soil and its pathogenic significance.

Species composition offungal biota. The species composition of fungal biota in the examined vegetables and adjacent soil represents a much greater risk for consumers than the total degree of contamination. The main cause is the prevalence of mycotoxin-producing strains belonging to the genera Penicillium and Fusarium which together form 40.5-73.9\% of total fungal isolates, exceeding $50 \%$ in 10 out of 12 kinds of samples (Fig. 1-2). A total of 61 species were identified in the examined samples of root vegetables and adjacent soil. The number of identified species was greater on conventional farms compared to organic ones (50 versus 35), indicating a higher biodiversity.

Incidence of potentially pathogenic species among the total fungal isolates. Of the 61 species of filamentous fungi determined in the examined root vegetables and adjacent soil (Tab. 2 and 3), 28 (45.9\%) were proved to be pathogenic for humans and/or animals [7, 15, 16] (Tab. 4). Among the potentially pathogenic species identified, 12 belonged to Penicillium genus, 4 to Fusarium genus, and 2 each to Aspergillus, Cladosporium and Trichoderma genera. The remaining species were single representatives of 6 various genera (Tab. 4). Most probably, the real number of pathogenic species present in the examined environment was greater, as only strains identified down to the species level were recognized in Table 4, whereas species determined to the generic level were not, in spite of the fact that the latter, such as Fusarium spp., Rhizomucor spp., or Lichtheimia (Absidia) spp., might also possess pathogenic properties.

Until recently, little was known about the occurrence of the species of filamentous fungi and/or mycotoxins in carrot and beetroot. Lugauskas et al. [8] isolated from carrots and carrot salads in Lithuania the species Sclerotinia sclerotiorum, Verticillium alboatrum, Fusarium proliferatum, F. moniliforme, F. redolens, Myrothecium roridum, $M$. verruraria, Aspergillus niger, Cladosporium cladosporioides, Geotrichum candidum, Synchytrium endobioticum, and abundant fungi of the genus Penicillium. Solfrizzo et al. $[17,18]$ demonstrated that the carrot strains of Alternaria alternata produced the mycotoxins tenuazonic acid (TeA), alternariol $(\mathrm{AOH})$, alternariol methyl ether (AME), and altertoxin-I (ATX-I), at levels between $0.5-3.0 \mu \mathrm{g} / \mathrm{g}$.

Mechanisms of the potential pathogenicity revealed by species isolated from vegetables and soil. The potential pathogenicity of species identified in carrot, beet and adjacent soil, was most often (in 14 cases) due to the production of mycotoxin(s) which cause mycotoxicoses in humans and animals, in 4 cases jointly to mycotoxin(s) production and ability of causing opportunistic infections, in 5 cases only 
Table 4. Pathogenic species of filamentous fungi isolated from root vegetables and adjacent soil

\begin{tabular}{|c|c|c|}
\hline Species & Pathogenicity & Produced mycotoxin(s) \\
\hline Acremonium strictum & opportunistic infections & \\
\hline Alternaria alternata & $\begin{array}{l}\text { mycotoxicoses, } \\
\text { allergic diseases }\end{array}$ & alternariol, alternariol monomethyl ether, altenuene, tenuazonic acid, altertoxin-I, others \\
\hline Aspergillus clavatus & $\begin{array}{l}\text { mycotoxicoses, } \\
\text { allergic diseases }\end{array}$ & cytochalasin E, cyclopiazonic acid, patulin \\
\hline Aspergillus versicolor & mycotoxicoses & $\begin{array}{l}\text { sterigmatocystin, versicolorin, } \\
\text { aspercolorin, averufin, others }\end{array}$ \\
\hline Chaetomium atrobruneum & $\begin{array}{l}\text { opportunistic infections } \\
\text { (brain abscess) }\end{array}$ & \\
\hline Cladosporium herbarum & allergic diseases & \\
\hline Cladosporium sphaerospermum & allergic diseases & \\
\hline Fusarium culmorum & mycotoxicoses & $\begin{array}{l}\text { numerous trichothecenes (T-1, T-2, HT-2, NT-1, NT-2, deoxynivalenol, neosolaniol, others), fumonisin } \\
\text { B1, moniliformin, zearalenon, others }\end{array}$ \\
\hline Fusarium proliferatum & $\begin{array}{l}\text { mycotoxicoses, } \\
\text { opportunistic infections } \\
\text { (mostly ocular) }\end{array}$ & fusaproliferin, fumonisin B1, moniliformin, others \\
\hline Fusarium solani & $\begin{array}{l}\text { mycotoxicoses, } \\
\text { opportunistic infections } \\
\text { (mostly ocular) }\end{array}$ & numerous trichothecenes (T-1, T-2, NT-2, neosolaniol, others) \\
\hline Mucor circinelloides & $\begin{array}{l}\text { opportunistic infections } \\
\text { (mucormycoses) }\end{array}$ & \\
\hline $\begin{array}{l}\text { Penicillium aurantiogriseum } \\
\text { (cyclopium) }\end{array}$ & $\begin{array}{l}\text { mycotoxicoses } \\
\text { (Balkan Endemic Nephropathy) }\end{array}$ & Viomellein, cyclopiazonic acid, patulin, ochratoxin A, verrucosidin, chaetoglobosin A \\
\hline $\begin{array}{l}\text { Penicillium chrysogenum } \\
\text { (notatum) }\end{array}$ & mycotoxicoses & ochratoxin A, patulin, cyclopiazonic acid, secalonic acid, PR toxin \\
\hline Penicillium citrinum & mycotoxicoses & citrinin, citreoviridin \\
\hline Penicillium corylophilum & mycotoxicoses & sesquiterpene phomenone, meroterpenoids, koninginins, a-pyrones, isochromans \\
\hline Penicillium crustosum & mycotoxicoses & peritrem A, cyclopiazonic acid, viomellein \\
\hline Penicillium digitatum & opportunistic infections & \\
\hline Penicillium expansum & mycotoxicoses & patulin, citrinin, cyclopiazonic acid, peritrem A, chaetoglobosin A \\
\hline Penicillium glabrum & $\begin{array}{l}\text { allergic diseases } \\
\text { (suberosis) }\end{array}$ & \\
\hline $\begin{array}{l}\text { Penicillium griseofulvum } \\
\text { (urticae) }\end{array}$ & mycotoxicoses & patulin, cyclopiazonic acid \\
\hline Penicillium nalgiovense & mycotoxicoses & cyclopiazonic acid \\
\hline Penicillium olsonii & mycotoxicoses & verrucolone \\
\hline Purpureocillium lilacinum & $\begin{array}{l}\text { opportunistic infections, } \\
\text { mycotoxicoses }\end{array}$ & paecilotoxins \\
\hline Rhizopus stolonifer & $\begin{array}{l}\text { opportunistic infections, } \\
\text { (mucormycoses) }\end{array}$ & \\
\hline Trichoderma harzianum & mycotoxicoses & harzianum A (trichothecene) \\
\hline Trichoderma viride & mycotoxicoses & $\begin{array}{l}\text { trichodermin, satratoxins } \mathrm{F}, \mathrm{G}, \mathrm{H} \\
\text { (trichothecenes) }\end{array}$ \\
\hline
\end{tabular}

to the ability to cause opportunistic infections, in the next 2 cases jointly to allergenic properties and mycotoxin(s) production, and, finally, in 3 cases, only to allergenic properties (Tab. 4).

The species isolated from root vegetables and soil produced at least 44 different mycotoxins that show a wide spectrum of pathogenic effects, targetting various organs in exposed humans and/or animals $[7,15,16,19]$. The majority revealed hepatotoxic and/or nephrotoxic properties, while some others, e.g. peritrem A produced by Penicillium crustosum are neurotoxic, exhibiting tremorgenic properties [20]. A significant risk is associated with exposure to mycotoxins supposed to possess carcinogenic properties, such as sterigmatocystin produced by Aspergillus versicolor [16].

The detection of a large number of mycotoxin-producing fungi inspired continuation of the mycological study in future by determining, with the use of an immunological method, the concentrations of selected mycotoxins in root 
vegetables. The presented work shows that such studies on the concentrations of both fungi and mycotoxins are highly desirable.

Some species detected in root vegetables and adjacent soil have been described as causative agents of opportunistic infections occurring mostly in the immunocompromised individuals. They include representatives of the class Zygomycetes, causing mucormycoses or zygomycosis (Rhizopus stolonifer, Mucor circinelloides), fungi of the genus Fusarium causing mostly ocular mycoses, and the species Acremonium strictum, Chaetomium atrobruneum, Penicillium digitatum, and Purpureocillium lilacinum [21].

At least 5 species of fungi, identified in the course of the present work as indigenous to root vegetables and/or soil, were reported as a cause of respiratory allergy, such as asthma and rhinitis (Alternaria alternata, Cladosporium herbarum, Cladosporium sphaerospermum) [22] or hypersensitivity pneumonitis (Aspergillus clavatus, Penicillium glabrum) [22].

Factors increasing health risk following consumption of vegetables contaminated with filamentous fungi.

Cross-reactivity between respiratory and oral allergens. According to Popescu [23], up to $80 \%$ of all cases of food allergy in adult patients are preceded by IgE-mediated sensitisation (clinical or subclinical) to aeroallergens. In these patients, food allergic symptoms are caused by crossreactions between ingested food and inhaled allergens sharing the same antigenic determinants. This view is in line with earlier experiments by Luccioli et al. [24] who demonstrated that oral challenge with mould extract elicited allergic symptoms in individuals sensitive to aeroallergenic moulds, and expressed a view that consumption of foods contaminated with fungi may trigger respiratory symptoms in people with allergy to airborne moulds.

As some fungal species detected in the present study in carrot and beet vegetables, such as Acremonium strictum, Alternaria alternata, Cladosporium herbarum, and Trichoderma viride, have been associated with clinical cases of respiratory allergy [23], it is probable that ingestion of spores or mycelium fragments of these fungi at consumption of root vegetables may elicit symptoms of food allergy which may be triggered even by low doses of adverse allergen [23].

Enzymatic activity of fungal strains isolated from root vegetables and adjacent soil. A potential risk associated with exposure to fungal strains associated with vegetables might be enhanced in the light of tests which revealed the presence of moderate enzymatic activity in all 13 strains tested. The stated ability to produce hydrolytic enzymes facilitates opportunistic infections by degradation of keratin and penetration of the mycelium into tissues [25]. It was also demonstrated that both carbohydrases and proteases produced by moulds may induce allergic and/or inflammatory reactions [26].

It is noteworthy that supplementation of test medium with the homogenous minced vegetable from which the tested fungal strain was isolated, significantly increased the enzymatic activity of this strain. These results are in line with those obtained by Żukiewicz-Sobczak et al. [25] who tested the enzymatic activity of fungal strains isolated from wheat and rye, and observed a distinct enhancement of this activity after supplementation of test medium with homogenous cereal. The authors of the current study believe that this observation may be useful in testing of enzymatic activity of fungi isolated from various foods.

Filamentous fungi in vegetables from organic versus conventional farming. Hypothetically, produce grown on organic farms could show a higher level of microbial contamination, compared to conventional ones, chiefly because the use of manure. However, comparative studies performed in various countries have not provided unequivocal support for this hypothesis [2, 4].

In the presented study, the comparison of mycological pollution of carrot grown on organic versus conventional farms showed the reverse tendency, as the levels of fungi in fresh vegetables and adjacent soil were significantly greater on conventional farms. The reason for that is unknown, the authors speculate that some constituents of mineral fertilizers used on conventional farms might stimulate the development of fungi. In the case of beetroot, the levels of fungi were also greater on conventional farms, but the difference did not attain a significance level.

It is noteworthy that fungal biota on conventional farms showed a distinctly greater biodiversity, as ascertained by the greater number of identified species.

\section{CONCLUSION}

Filamentous fungi occur on root vegetables cultivated in eastern Poland at levels that may be classified as moderate. Nevertheless, they pose a real health risk for some categories of consumers because of the high proportion of potentially pathogenic species of soil origin, mainly from the genera Penicillium and Fusarium, that produce mycotoxins, exhibit allergenic properties, or cause opportunistic infections. The ingestion of root vegetables contaminated with potentially pathogenic fungi could be especially dangerous for immunocompromised individuals, in particular those subjected to immuno-suppression treatment in health care units. Another endangered category are people with atopy, susceptible to IgE-mediated allergy, exhibiting respiratory hypersensitivity to airborne moulds, in which ingested fungi may elicit a pathogenic cross-reaction. Less probable are outbreaks of gastrointestinal disease in healthy people, similar to those caused by enteric bacteria.

In contrast to theoretic speculations, there was no significant difference between concentrations of filamentous fungi in beetroots grown on organic and conventional farms, whereas fungal concentrations in carrots were significantly greater on conventional farms.

Summarizing, root vegetables may play the role of a vehicle transmitting potentially pathogenic fungi from soil to the human organism by the oral route. To prevent negative effects of the ingestion of contaminated vegetables, it is recommended to avoid eating raw vegetables by endangered individuals (immuno-compromised persons, people with atopy). To prevent post-harvest development of potentially pathogenic filamentous fungi, it is very important to assure proper storage conditions of root vegetables at low temperature and humidity. As an element of prophylaxis, an institutionally-based enhancement of the scope of mycological examination of vegetables could be considered. 


\section{REFERENCES}

1. Jung Y, Jang H, Matthews KR. Effect of the food production chain from farm practices to vegetable processing on outbreak incidence. Microbiol Biotechnol. 2014; 7(6): 517-527.

2. Maffei DF, Batalha EY, Landgraf M, Schaffner DW, Franco BD. Microbiology of organic and conventionally grown fresh produce. Brazilian J Microbiol. 2016; 47 (Suppl 1): 99-105.

3. Oliveira M, Usall J, Vinas I, Anguera M, Gatius F, Abadias M. Microbiological quality of fresh lettuce from organic and conventional production. Food Microbiol. 2010; 27: 679-684.

4. Tango CN, Choi NJ, Chung MS, Oh DH. Bacteriological quality of vegetables from organic and conventional production in different areas of Korea. J Food Protection. 2014; 77(8): 1411-1417.

5. Szczech M, Kowalska B. Microbiological quality of organic vegetables. Nowości Warzywnicze 2010; 51: 65-72 (in Polish).

6. Cabral Machado D, Marques Maia C, Dias Carvalho I, Fontoura da Silva $\mathrm{N}$ et al. Microbiological quality of organic vegetables produced in soil treated with different types of manure and mineral fertilizers. Braz. J. Microbiol. 2006; 37(4): 538-544.

7. Barkai-Golan R, Paster N. Mycotoxins in fruits and vegetables. San Diego: Academic Press. 2008.

8. Lugauskas A, Repečkienė J, Levinskaitė L, Mačkinaitė R, Kačergius A, Raudonienè V. Micromycetes as toxin producers detected on raw material of plant origin grown under various conditions in Lithuania. Ekologija. 2006; 3: 1-13.

9. Kwaśna H, Chełkowski J, Zajkowski P. Fungi. Volume XXII. Institute of Botany, PAN, Kraków 1991 (in Polish).

10. Samson R.A., Houbraken J, Frisvad JC, Andersen B. Food and Indoor Fungi; CBS-KNAW 2010 Fungal BiodiwerCity Centre Utrecht.

11. Watanabe T. Pictorial Atlas of Soil and Seed Fungi; CRC Press, Boca Raton, USA 2010.

12. Abadias M, Usall J, Anguera M, Solsona C, Viñas I. Microbiological quality of fresh, minimally-processed fruit and vegetables, and sprouts from retail establishments. Int J Food Microbiol. 2008; 123(1-2): 121129.

13. Maffei DF, Silveria N, Catanozi M. Microbiological quality of organic and conventiolal vegetables sold in Brazil. Food Control 2013; 29(1): $226-230$.
14. Kłapeć T, Cholewa A, Cholewa G, Dutkiewicz J, Wójcik-Fatla A Microbiological characterization of vegetables and their rhizosphere soil in eastern Poland. Ann Agric Env Med. 2016; 23(4): 559-565.

15. Marin S, Ramos AJ, Cano-Sancho G, Sanchis V. Mycotoxins: Occurrence, toxicology, and exposure assessment. Food Chem Toxic. 2013; 60: 218-237.

16. Lillard-Roberts S. Mycotoxin list. Boletim Científico 2017; No. 46. Available at http://www.micotoxinas.com.br Accessed 20.01.17.

17. Solfrizzo M, De Girolamo A, Vitti C, Visconti A Van Den Bulk R. Liquid chromatographic determination of Alternaria toxins in carrots. JAOAC International. 2004; 87: 101-106.

18. Solfrizzo M, Girolamo AD, Vitti C, Tylkowska K, GrabarkiewiczSzczęsna J, Szopińska D, et al. Toxigenic profile of Alternaria alternata and Alternaria radicina occurring on umbelliferous plants. Food Addit Contam. 2005; 22(4): 302-308.

19. Kuhn DM, Ghannoum MA. Indoor mold, toxigenic fungi, and Stachybotrys chartarum: infectious disease perspective. Clin Microbiol Rev. 2003; 16(1): 144-172.

20. Moldes-Anaya A., Rundberget T, Fæste CK, Eriksen GS, Bernhoft A. Neurotoxicity of Penicillium crustosum secondary metabolites: tremorgenic activity of orally administered penitrem $\mathrm{A}$ and thomitrem A and E in mice. Toxicon. 2012; 60(8): 1428-1435.

21. Farmakiotis D, Kontoyiannis DP. Mucormycoses. In L. OstroskyZeichner, L. Sobel (Eds.), Fungal Infections, Special Issue of Infectious Disease Clinics of North America. 2016; 30: 143-163.

22. Inspect Apedia. Mold atlas of indoor clinical mold, pathogens, allergens \& other indoor particles. Available at htpp://inspectapedia.com/mold. 2017. Accessed 01.02.17

23. Popescu FD. Cross-reactivity between aeroallergens and food allergens. World J Methodol. 2015; 5(2): 31-50.

24. Luccioli, S, Malka-Rais J, Osnuli TM, Bellanti, JA. Clinical reactivity to ingestion challenge with mixed mold extract may be enhanced in subjects sensitized to molds. Allergy Asthma Proceedings. 2009; 30(4): 433-442

25. Żukiewicz-Sobczak WA., Cholewa G, Sobczak P, Silny W, Nadulski R, Wojtyła-Buciora P, et al. Enzymatic activity of fungiisolated from crops. Adv Dermatol Allergol. 2016; 33(6): 457-463.

26. Yike I. Fungal proteases and their pathophysiological effects. Mycopathologia. 2011; 171(5): 299-323 